\title{
Correction: Lenalidomide added to standard intensive treatment for older patients with AML and high-risk MDS
}

G. J. Ossenkoppele - D. A. Breems - G. Stuessi - Y. van Norden • M. Bargetzi • B. J. Biemond • P. A von dem Borne · Y. Chalandon (1) - J. Cloos • D. Deeren - M. Fehr • B. Gjertsen · C. Graux · G. Huls • J. J. J. W. Janssen - A. Jaspers · M. Jongen-Lavrencic - E. de Jongh · S. K. Klein · M. van der Klift $\cdot$ M. van Marwijk Kooy $\cdot$ J. Maertens $\cdot$ L. Michaux M. W. M. van der Poel · A. van Rhenen - L. Tick · P. Valk · M. C. Vekemans · W. J. F. M. van der Velden · O. de Weerdt • T. Pabst $\cdot$ M. Manz $(\mathbb{D} \cdot$ B. Löwenberg $\cdot$ for the Dutch-Belgian Hemato-Oncology Cooperative Group (HOVON) and Swiss Group for Clinical Cancer Research (SAKK)

Published online: 30 July 2020

(c) The Author(s), under exclusive licence to Springer Nature Limited 2020

Correction to: Leukemia

https://doi.org/10.1038/s41375-020-0725-0

The original version of this Article contained an error in the spelling of the author Lucienne Michaux, which was incorrectly given as Lucienne Micheaux. This has now been corrected in both the PDF and HTML versions of the Article. 